Tensions between constitutional legality and the democratic principle in the Spanish Constitution of 1978

\title{
Tensiones entre la legalidad constitucional y el principio democrático en la Constitución española de 1978
}

Juan Antonio Fernández Manzano

Universidad Complutense de Madrid jafern01@ucm.es

DOI: https://doi.org/10.15366/bp2019.22.015

Bajo Palabra. II Época. No 22. Pgs: 291-308

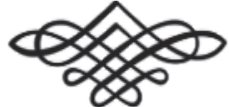


Recibido: 18/04/2019

Aprobado: 02/10/2019

\section{Resumen}

El trabajo analiza algunas deficiencias de la Constitución española de 1978 desde la premisa de que los límites constitucionales que pueden imponerse al ejercicio de la soberanía popular en democracia nunca pueden exceder, so pena de perder su legitimidad, el mínimo necesario para garantizar la inviolabilidad de los derechos que se consideran esenciales para la convivencia pacífica. Sin embargo, se argumenta que algunas de las restricciones, fruto del contexto en el que fueron redactadas, exceden este límite y son cuestionables en la medida en que suponen un impedimento para alcanzar los principales objetivos que la misma Constitución dice defender desde su inicio.

Palabras clave: Constitución española, democracia, Estado, soberania popular.

\section{Abstract}

The paper analyses some deficiencies of the Spanish Constitution of 1978 from the premise that the constitutional limits that may be imposed on the exercise of popular sovereignty in a democracy can never exceed, without losing its legitimacy, the minimum necessary to ensure the inviolability of the rights considered essential for peaceful coexistence. However, it is argued that some of the restrictions detected, the result of the context in which they were written, do exceed this limit and can be considered illegitimate as they pose an impediment to achieving the main goals that the Constitution claims to defend from its inception.

Keywords: Spanish Constitution, democracy, state, popular sovereignty. 
$\mathrm{E}$ n términos generales, una Constitución, en tanto que es la norma que establece el orden jurídico más alto de una sociedad, protege e irradia en el resto de leyes los valores mínimos compartidos. En el marco de un Estado social y democrático de derecho, uno de sus fines fundamentales ha de ser el de articular el ejercicio democrático, garantizando el respeto a estos valores, que pueden considerarse como los pilares estructurales de la sociedad. La cuestión a analizar es el modo de modular el ejercicio democrático atendiendo al valor superior de lo que se estiman como derechos y libertades fundamentales.

Partimos de la idea de que los textos constitucionales de las democracias constitucionales, a diferencia de las democracias procedimentales, articulan leyes e instituciones con el objetivo de salvaguardar la dignidad de las personas del acceso de interferencias arbitrarias y prevenir la sempiterna tentación de los gobernantes de subordinar los derechos y libertades de los ciudadanos a objetivos de menor consideración. ${ }^{1}$ Pero incluso las democracias procedimentales, carentes de limitaciones constitucionales sobre la legislación y que en principio tienen la capacidad de convertir en ley todo lo decidido por las mayorías, han de contar y de hecho cuentan en sus prácticas con un conjunto de normas básicas que determinan las condiciones y procedimientos que una norma debe cumplir para tener validez en un ordenamiento jurídico. Es esto a lo que $\mathrm{Hart}^{2}$ denomina la regla de reconocimiento, una metanorma convencional, en su caso implícitamente aceptada, a la que las normas deben adecuarse para ser válidas o a lo que Bobbio, con variantes que no nos interesa ahora destacar, denomina normas sobre la producción jurídica. ${ }^{3}$

En todo caso, un régimen constitucional democrático ha de asegurar la consistencia entre sus leyes y el respeto de los derechos y libertades básicos como la libertad de expresión, la libertad de conciencia, el derecho de asociación, el derecho a la presunción de inocencia, el derecho a la participación política y el derecho al voto. Para ello establece una serie de impedimentos técnicos que restrinjen la derogación de dichas garantías, a las que se considera esencias constitucionales.

\footnotetext{
${ }^{1}$ Rawls, J., La justicia como equidad. Una reformulación, edición a cargo de Erin Kelly, traducción de Andrés de Francisco, Barcelona, Paidós, 2002, p. 196.

2 Hart, H. L. A., The Concept of Law, Oxford, Oxford University Press, 1961, cap. 5 y 6.

${ }^{3}$ Bobbio, N., "Per un lessico di teoria generale del diritto" (1975), en Bobbio, N., Contributi ad un dizionario giuridico, Torino, 1994, p. 233.
} 
Naturalmente, estos obstáculos significan en la práctica una limitación de la acción del legislativo y por tanto, una merma de la propia soberanía, pues determinados contenidos constitucionales no serían susceptibles de alteraciones y quedarían por encima de la capacidad del soberano, al menos en el ejercicio ordinario de su función. Tal limitación de la soberanía estaría, no obstante, justificada en razón del superior valor de los bienes cuya continuidad se desea proteger y sería, por paradójico que parezca, la condición de posibilidad de la propia democracia, ${ }^{4}$ en la medida en que los ciudadanos, antes de poder auto-legislarse, necesitan primeramente reconocerse unos a otros como iguales en dignidad, derechos y libertades. ${ }^{5}$

Este trabajo parte de la aceptación de estas premisas y sostiene, adicionalmente, que los límites constitucionales que pueden imponerse al ejercicio de la soberanía popular en democracia nunca pueden exceder, so pena de perder su legitimidad democrática, el mínimo necesario para garantizar la inviolabilidad de los derechos y libertades que la propia sociedad considera esenciales para respetar la dignidad de sus miembros y la convivencia pacífica. Los derechos y libertades, como afirma Rawls, solo pueden restringirse en beneficio de los propios derechos y libertades. ${ }^{6}$ En ese sentido, las limitaciones impuestas a las libertades han de derivar del respeto a derechos ampliamente reconocidos. Así, por ejemplo, la libertad de reunión está limitada y no ampara las reuniones con fines delictivos o la libertad de expresión no permite violar el derecho al honor de otras personas. Lo que sostenemos es que aquellas restricciones de la soberanía que no queden justificadas por la protección de derechos o libertades básicos pueden ser, en principio, cuestionadas.

Partiendo de esta perspectiva, procederemos a estudiar cómo se resuelve la tensión entre la protección de los derechos y libertades y las restricciones de la soberanía en la actual Constitución Española.

En lo referido a los bienes comunes fundamentales merecedores de la más alta protección, la Constitución Española de 1978 cita en su preámbulo la seguridad, la integridad física y moral; la convivencia, basada en el respeto a la dignidad de la persona y sus derechos inviolables [Tít. I, art. 10]; el imperio de la ley como expresión de la voluntad popular y la protección de los derechos humanos. En el apartado uno del artículo primero del Título Preliminar se propugnan como valores superiores del ordenamiento jurídico la libertad, la justicia, la igualdad y el pluralismo político. La defensa de estos derechos y libertades fundamentales,

\footnotetext{
${ }^{4}$ Holmes, S., "Precommitment and the Paradox of Democracy", en J. Elster y R. Slagstad (eds.), Constitutionalism and Democracy, Cambridge, Cambridge University Press, 1988, pp. 195-240. https://doi.org/10.1017/ CBO9781139173629.008

5 Habermas, J., Facticidad y validez. Sobre el derecho y el Estado democrático de derecho en términos de teoría del discurso, introducción y traducción de M. Jiménez Redondo, Madrid, Trotta, 1998, p. 169.

${ }^{6}$ Rawls, J., El liberalismo político, traducción de Antoni Domènech, Barcelona, Crítica, 1996, p. 332.
} 
socialmente reconocidos, constituye la piedra angular de la vigente Constitución española de 1978.

En lo tocante a la soberanía, el Título Preliminar afirma que España se constituye en un Estado social y democrático de Derecho (art. 1.1) y que la soberanía reside en el pueblo español, del que emanan los poderes del Estado (art. 1.2). El ciudadano es por tanto, el origen, el destino y la legitimación de la Ley. Así, en el art. 23 del capítulo II, referido a derechos y libertades, se reconoce el derecho de los ciudadanos a participar en los asuntos públicos, directamente o por medio de representantes libremente elegidos. En el apartado 1 del artículo 53 del capítulo IV se afirma que el ejercicio de los derechos y libertades vincula a todos los poderes públicos y que, en efecto, puede regularse por ley (y por tanto limitarse), siempre y cuando no se altere su contenido esencial.

Por tanto, la Constitución española de 1978 ampara la expresión (directa e indirecta) de la voluntad popular y la posibilidad de su limitación si se ponen en riesgo valores fundamentales, tratando de no alterar el contenido básico de los derechos y libertades. Sin embargo, como trataremos de mostrar, determinadas restricciones a la expresión de la soberanía popular no obedecen a estas razones y por tanto no pueden ser consideradas como el mínimo necesario para garantizar la inviolabilidad de los derechos y valores fundamentales. La limitaciones a la participación popular de las que hablamos son las referidas a la posibilidad ciudadana de proponer reformas en las normas vigentes, tanto de rango constitucional como ordinario.

La Constitución prevé dos procedimientos de reforma, regulados en los artículos 167 y 168 respectivamente. El primero es el procedimiento ordinario, para el que se exige la aprobación de $3 / 5$ de cada cámara. ${ }^{7}$ Posteriormente, y solo si lo solicita 1/10 parte de los miembros de cualquier cámara, se realizaría un referéndum para su ratificación, que no sería obligatorio, al tratarse de una reforma ordinaria. El segundo es el procedimiento agravado. Se trata de un procedimiento extraordinario para reformas integrales de la Constitución o para una reforma parcial que afecte al Título Preliminar, al capítulo II, sección primera del Título I (referido a los derechos fundamentales y de las libertades públicas) o al Título II (asuntos referidos a la Corona, como su carácter hereditario, la inviolabilidad del monarca o su irresponsabilidad).

Para una reforma de este tipo, que se considera como abrir un nuevo proceso constituyente, se requieren trámites aun más rígidos y complejos: la aprobación por mayoría de $2 / 3$ de cada una de las cámaras, la posterior disolución de las cámaras

\footnotetext{
O en caso de no alcanzarse, se constituye una comisión constitucional paritaria integrada por miembros de ambas cámaras que presenta un nuevo texto. Con una mayoría absoluta en el senado se exige en el congreso una mayoría de $2 / 3$.
} 
tras la aceptación de la reforma y la ratificación de la aceptación del nuevo texto por parte de las dos nuevas cámaras mediante mayoría de $2 / 3$ de cada una. Además se exigiría la ratificación por referéndum de los ciudadanos.

Revisando la historia reciente encontramos que la constitución española se mantuvo inalterable desde su aprobación hasta la primera reforma de 1992, mediante una proposición conjunta, ${ }^{8}$ presentada el 7 de julio de 1992, referida al ejercicio del derecho de sufragio de los extranjeros en las elecciones municipales. ${ }^{9}$ Se trataba en este caso de una exigencia del Tratado de Maastrich.

La segunda reforma (2011) modificó el artículo 135 de la Constitución. El artículo resultante de esta reforma exige que todos los poderes públicos adapten sus acciones al principio de estabilidad presupuestaria, dando prioridad del pago de la deuda y los intereses. La propuesta fue hecha por el Presidente el 23 de agosto de 2011. ${ }^{10}$ Se trató de una reforma muy controvertida, pues considera la estabilidad presupuestaria como un principio constitucional.

Por lo que respecta a nuestro análisis, nos parece destacable observar que las dos únicas reformas constitucionales se realizaron por iniciativa del gobierno o siguiendo demandas externas. En ambos casos se trató de una exigencia derivada de la pertenencia a la Unión Europea y en ninguna de ellas se convocó un referéndum para pulsar la voluntad de los ciudadanos. Esto fue posible porque el artículo 166 (Título X) establece que la iniciativa de reforma constitucional debe ejercerse en los términos dispuestos en los apartados 1 y 2 del artículo 87, que afirman que la iniciativa legislativa corresponde al Gobierno, al Congreso y al Senado. ${ }^{11}$

A diferencia de lo que sucede en países como la Confederación Helvética, Letonia, Lituania, Rumanía y Austria, actualmente no se reconoce el derecho de los ciudadanos ni siquiera a solicitar a sus representantes que estudien una reforma constitucional ni ordinaria ni agravada por la vía de una iniciativa popular, a pesar de que tal posibilidad sí se llegó a contemplar en el Anteproyecto de nuestra Constitución en su artículo 157.

La iniciativa popular legislativa que se contempla en el artículo 87.3 de la Constitución (con un número de firmas no inferior a 500.000) excluye de la iniciativa legislativa, además de la propia Constitución y lo referido al desarrollo de derechos y

${ }^{8}$ A cargo de los grupos parlamentarios en el Congreso de PSOE, Partido Popular, Convergència i Unió, Izquierda Unida-Iniciativa per Catalunya, CDS, PNV y Grupo Mixto.

9 El artículo 13.2 quedó redactado así tras la reforma: "Solamente los españoles serán titulares de los derechos reconocidos en el artículo 23, salvo lo que, atendiendo a criterios de reciprocidad, pueda establecerse por tratado o ley para el derecho de sufragio activo y pasivo en las elecciones municipales."

${ }^{10}$ Contó con el apoyo del Grupo Parlamentario Socialista, Partido Popular y UPN

11 También se reconoce la posibilidad de que las Asambleas de las Comunidades Autónomas soliciten al Gobierno la adopción de un proyecto de Ley. 
libertades ciudadanas fundamentales, determinadas materias como las leyes orgánicas del Código Penal, los estatutos de autonomía, las leyes de educación, las leyes del Tribunal Constitucional, la ley electoral, la ley de partidos políticos, las leyes tributarias o de carácter internacional, los presupuestos o la prerrogativa de gracia e indulto.

Estas son cuestiones vetadas para el ejercicio democrático directo. Los teóricos titulares de la soberanía no pueden demandar la reforma de la norma básica que rige su convivencia en asuntos como la forma del Estado, su jefatura, la organización territorial, incluida la secesión de una parte del territorio, la ley electoral o la ley de partidos políticos.

Por mayoritaria que sea la iniciativa popular, los ciudadanos no tienen posibilidad efectiva de influir de forma directa en el poder legislativo en estos asuntos. ${ }^{12} \mathrm{La}$ gestión de lo público no pasa directamente por las manos del público. Sostenemos que esta es una limitación de la soberanía no ligada a la protección de valores fundamentales y que por tanto, entra en contradicción con el antedicho artículo 1.2 que declara que la "soberanía nacional reside en el pueblo espańol, del que emanan los poderes del Estado".

El proceso de reforma constitucional queda en consecuencia mediatizado por las reglas de distribución de votos y escańos que marca una ley electoral que es controlada por sus mayores beneficiarios: los grandes partidos políticos, lo que pone en entredicho el principio de minoría o el principio de la igualdad del valor del voto.

Otro tanto sucede con los referendos legislativos. El referéndum legislativo por iniciativa popular, aceptado en países como Italia, Irlanda, Dinamarca, Austria, Estados Unidos, Confederación Helvética, Alemania o Uruguay no se contempla en la actual Constitución, a pesar de haber sido parte del artículo 85 del Anteproyecto de Constitución.

El actual artículo 92 afirma que las decisiones políticas de especial trascendencia podrán ser sometidas a referéndum consultivo de todos los ciudadanos que será convocado por el Rey, mediante propuesta del presidente del Gobierno, previamente autorizada por el Congreso de los Diputados. No se contempla la posibilidad de que el referéndum sea convocado a iniciativa de un determinado número de electores. Tampoco se considera que el resultado del referéndum pueda ser vinculante; su carácter, de producirse, sería meramente informativo. No se permite en suma, ni la posibilidad de cuestionamiento popular de leyes votadas por las Cortes Generales y aún no sancionadas ni la posibilidad de derogación de leyes en vigor.

Esto permite afirmar que la Constitución española vigente se pueda clasificar como rígida en lo que respecta a las posibilidades de reformas populares que partan

12 Cf. art. 29 y 87.3 
de la iniciativa de los ciudadanos. Muestra de ello es que de las 66 iniciativas legislativas populares que han sido presentadas en el Congreso desde 1977, cada una de ellas suscrita por al menos medio millón de ciudadanos, solo dos han sido admitidas. ${ }^{13} \mathrm{~A}$ pesar del alto número de firmas que requiere y de los requisitos y controles a los que se somete, su uso queda excluido en materias políticas de envergadura, que pasan a ser tabú. Estas restricciones merman la participación directa de los ciudadanos en áreas de singular relevancia política y en la práctica deterioran lo que podría ser un instrumento de mejora democrática que aumentaría la implicación política ciudadana y la cultura cívica.

En estos casos, los ciudadanos carecen de medios directos para instar a modificar la Constitución o sus leyes y quedan bajo la tutela del gobierno o de las Cámaras de representación. ${ }^{14}$ En principio, la rigidez constitucional tendría su razón de ser si se orientara a evitar cambios emocionales o reformas coyunturales por parte de las mayorías en el poder o si tratara de evitar posibles vulneraciones de derechos fundamentales, pero en la práctica, lo que se hace es impedir la participación de los ciudadanos en decisiones políticas que legítimamente les competen, lo cual es un déficit democrático no justificado.

Las causas de esta rigidez y del déficit democrático se pueden encontrar en la particular transición española a la democracia. La Constitución de 1978 es una norma que nació condicionada por la relación de fuerzas que se dieron en el momento de su redacción. A pesar del esfuerzo de abstracción e idealización de los constituyentes, toda norma jurídica es, y esta en muy gran medida, un producto de la realidad en la que es elaborada y aprobada. La España de la transición presentaba unas características específicas y extraordinarias que imponían una serie de necesidades urgentes y de condicionantes evidentes. La Constitución española nació en un contexto político excepcional, precedida de una guerra civil y una larga dictadura. El equilibrio de poderes era muy desigual: los movimientos conservadores de derecha tenían una presencia muy notable en las estructuras de poder y por su parte, muchas de las fuerzas democráticas de la oposición llegaban del exilio o de la cárcel. El miedo de las fuerzas conservadoras a la libre expresión de la voluntad popular hizo que abundaran los filtros, restricciones y los intérpretes autorizados de la voluntad ciudadana. Sirva como ejemplo el hecho que se estipula en el artículo 92 con respecto al carácter no vinculante de los referendos.

Es de sobra conocido que la transición española a la democracia se llevó a cabo utilizando las estructuras del régimen franquista. El proceso constituyente se gestó

\footnotetext{
${ }_{13}^{13}$ Una de ellas sobre reclamación de deudas comunitarias y otra sobre la tauromaquia como patrimonio cultural. 14 Cf. art. 166.
} 
en el seno del régimen anterior, sin romper formalmente con su orden legislativo. Lo que se hizo fue introducir una nueva Ley Fundamental cuyo objeto era la modificación sustancial de las anteriores Leyes Fundamentales. La nueva Ley para la Reforma Política (Ley 1/1977, de 4 de enero) fue empleada para desactivar las hasta entonces vigentes leyes franquistas, aunque se mantuvo la inercia de mantener a los ciudadanos tutelados y no contar con su participación real. El contexto histórico de su redacción nos ayuda a entender por qué la Constitución ampara mecanismos democráticos de representación tutelada pero ni los desarrolla ni abre margen suficiente a vías de participación democrática directa como el referéndum o las iniciativas populares legislativas o constitucionales.

Por tanto, la Constitución de 1978, aunque indudablemente inaugura un nuevo modelo de Estado, está cargada de influencias del pasado inmediato que afectan notablemente a sus contenidos. Acaso uno de los ejemplos más notorios fuera la inexistencia de debate, mucho menos de referéndum, sobre algo tan trascendental como el modelo de Estado y su jefatura. La elección de la monarquía y el nombramiento del rey Juan Carlos I por las Cortes franquistas de 1.975 se hurtó del foro democrático y no se sometió a discusión pública, quedando en manos de los constituyentes.

No obstante, a pesar de las deficiencias democráticas, el grado de cuestionamiento o de crítica hacia la actual Constitución ha sido, hasta hace relativamente poco, ciertamente bajo. El mito de la conciliación pacífica de todos los españoles tras la dictadura y la guerra civil llevaron a la santificación cuasi-mítica de la actual Carta Magna bajo el supuesto de que la alteración de su equilibrio podría socavar la estabilidad y la paz social, sin duda valiosa, disfrutada bajo su amparo. Esto ha cambiado y aumentan las voces críticas que denuncian que la Constitución vigente no es el resultado de un proceso constituyente plenamente democrático, sino que fue erigida desde un marco de asimetría negociadora basada en una desigual relación de poder y que, por tanto, no puede sino considerarse una solución temporal, un acuerdo de compromiso, con sus virtudes y sus carencias. Una solución a la que Rawls definiría como un modus vivendi, para distinguirlo de un consenso constitucional profundo con bases sólidas. ${ }^{15}$

A esto cabe añadir que la sociedad de hoy es indudablemente muy diferente a la de los años setenta del siglo pasado. Compárese como anécdota tecnológica, la España de las centralitas telefónicas de clavijas con la de los móviles inteligentes de última generación.

Además, una buena cantidad de los españoles de hoy, los actualmente menores de 59 ańos, no tuvieron la oportunidad de votar por la Constitución de 1978 y

${ }_{15}$ Rawls, El liberalismo político, op. cit. 
por último, pero no lo menos importante, muchos de los actuales debates sociales y problemas políticos no son los mismos. Cuestiones como la forma y Jefatura del Estado o los movimientos independentistas plantean retos que cuestionan el actual ordenamiento constitucional, cuyo bloqueo jurídico impide el abordaje o la resolución de estos conflictos dentro del principio de legalidad. Creemos que la eficacia de un sistema jurídico no se mide por su capacidad de imponer coactiva y persistentemente un ordenamiento legal aun cuando su respaldo sea cuestionado, sino por su capacidad para dar respuestas dentro de la ley que acomoden las expectativas razonables de las nuevas mayorías y que no obturen las posiciones minoritarias. Esto es especialmente relevante en estados plurinacionales como el español, en el que lo que está en cuestión es la reforma de las propias bases constitucionales. ${ }^{16}$

La rigidez general del ordenamiento jurídico parece estar reñida en este caso con su estabilidad. Así, no es de extrańar que se desgaste la confianza de los ciudadanos en las instituciones democráticas y que más del $70 \%$ de los encuestados califiquen la situación política general de España como mala o muy mala y más de un 64\% crean que dentro de un año la situación política del país será igual o peor. ${ }^{17}$

La democracia como sistema no está cuestionada, pero se ha intensificado la percepción de que quienes deberían encargarse de su funcionamiento no lo hacen adecuadamente. El hecho de que un $29,4 \%$ de los encuestados consideren que los políticos en general, los partidos y la política son los problemas fundamentales del presente, por detrás tan solo del paro, ${ }^{18}$ es un hecho preocupante que impide que las instituciones gocen de la vida y perdurabilidad que les proporcionaría la confianza ciudadana y el necesario compromiso cívico con su cuidado.

Es útil recordar que la inercia de las instituciones, como nos recuerda Rawls con respecto a las condiciones de justicia, conduce inevitablemente hacia la degeneración, a menos que se arbitren mecanismos de ajuste. ${ }^{19}$ Dicho en otros términos, para que el marco institucional cumpla las funciones para las que fue diseñado es necesario el impulso del compromiso ciudadano y para que este, a su vez, pueda darse es vital no hacerlo depender ni de la coacción estatal ni de la tradición, sino de la renovación del acuerdo en torno a las esencias constitucionales, en tanto que bases de la cooperación política. Mientras haya acuerdo en torno a las esencias constitucionales y se perciba que son el resultado de un pacto en el que los ciudadanos han sido tenidos en consideración, hay esperanza de que la cooperación social y

\footnotetext{
${ }^{16}$ Aláez Corral, B., "Constitucionalizar la secesión para armonizar la legalidad constitucional y el principio democrático en Estados territorialmente descentralizados como Espańa”, REAF núm. 22, octubre 2015, pp. 136-183.

${ }_{17}$ CIS, Estudio no 3240, Barómetro de febrero, 2019.

${ }^{18}$ Ibíd.

19 Rawls, El liberalismo politico, op. cit.
} 
política pueda seguir dándose, de lo contrario, la legitimidad se empieza a quebrar y la estabilidad peligra. ${ }^{20}$ Más allá de la elección de gobernantes, el pueblo necesita de recursos legales que permitan mantener el flujo permanente de poder desde los gobernados a los gobernantes.

De ahí que sea difícil exagerar la importancia de fomentar la participación de los ciudadanos en procesos políticos deliberativos y la profundización de la democracia participativa. La legitimidad que requiere la estabilidad política exige la percepción ciudadana de que sus instituciones son verdaderamente representativas y que ellos son considerados parte activa del sistema político. ${ }^{21}$

Aceptar la profundización democrática supone asumir que una de sus consecuencias es la ampliación del potencial de impredecibilidad del juego político. Si asumimos, con Arendt, que la política democrática es un diálogo en un espacio de libertad cuyos resultados son permanentemente abiertos y no siempre previsibles, hemos de aceptar que la ciudadanía plena puede desear poder empezar algo nuevo y sentar nuevos comienzos. ${ }^{22}$

Si se asume que una de las esencias de la política es el conflicto y la pluralidad de voces, es necesario entender que toda reducción de lo plural a la unidad es estructuralmente inestable. El pluralismo es un rasgo permanente e irreductible de toda cultura democrática en condiciones de libertad y por tanto, no hay posibilidad de erradicar el antagonismo apelando a valores como la razón, el derecho, la justicia, la moral, la cohesión, el entendimiento o la convivencia, porque el antagonismo es constitutivo y consustancial a la política. Decía Spinoza que quienes se imaginan que es posible que los que están divididos por los asuntos públicos lleguen a una convergencia según el exclusivo mandato de la razón, "sueñan con el siglo dorado de los poetas o con una fábula". ${ }^{23}$

Cuando Rawls insta a reconocer las cargas del juicio se está haciendo cargo de que ni siquiera los intentos más sinceros de llegar a acuerdos aplicando bienintencionadamente nuestras facultades de razón y juicio tienen garantizado el éxito, especialmente en los juicios políticos, donde las cuestiones son complejas, las evidencias conflictivas, y los conceptos en juego poseen una textura abierta e interpretable. Esto fuerza a instalar la política en un ámbito en el que los "desacuerdos razonables" son una posibilidad no descartable. ${ }^{24}$ No se trata de que las divisiones, el disenso o los conflictos surjan de la mala fe o la defensa de intereses

\footnotetext{
${ }^{20}$ Rawls, La justicia como equidad. Una reformulación, op. cit., p. 53

${ }^{21}$ Kelsen, H., Esencia y valor de la democracia, traducción de R. Luengo y L. Legaz, prólogo de I. de Otto, Barcelona, Labor, 1977.

22 Arendt, H., ¿Qué es política? traducción de Rosa Sala Carbó, Barcelona, Paidós, 1997.

23 Spinoza, B., Tratado Politico, traducción de Atilano Domínguez, Madrid, Alianza, 1986, I, 5.

${ }^{24}$ Rawls, La justicia como equidad. Una reformulación, op.cit., pp. 62ss.
} 
inconfesables, que también, sino que hay un conflicto más radical que es inseparable de lo político.

Todo ello nos lleva a afirmar que el orden político es precario y que si el conflicto no puede ser extirpado apelando a la ciencia, el derecho o la razón, mucho menos puede disolverse recurriendo a la fuerza coercitiva del Estado. Por un lado, las llamadas al consenso y a la armonía ignoran la pluralidad del escenario político; por otro, el uso de la fuerza trata de extirparla. En ambos supuestos, el tecnocrático y el coercitivo, se distorsiona lo más propio de la política: la aceptación del contrario. ${ }^{25}$

Parece pues más realista mantener abiertos los espacios en los que los posibles conflictos se muestren, no con la intención de apaciguarlos, sino con el fin de que se articulen, se expresen y arranquen nuevos comienzos, llegado el caso. Las identidades colectivas y las posiciones políticas no son inalterables, están en constante construcción y reelaboración y solo un espacio de democracia y libertad puede impedir que el antagonismo degenere en violencia. Asumir esta tesis en toda su extensión implica que los consensos pueden no darse. La capacidad del Estado como instrumento para minimizar las diferencias y generar nación allí donde no la hay es limitada. Un proyecto de Estado republicano con un concepto de nación inclusivo y desligado de connotaciones autoritarias es tal vez la única vía que permita acomodar el pluralismo interno, pero ello no puede realizarse tratando de ahormar las diferencias bajo esencias constitucionales no compartidas y férreamente establecidas. Reivindicar el papel de la política en contextos democráticos, más allá de la retórica, implica necesariamente asumir que el adversario político tiene también sus razones y que estas pueden rebasar el propio marco constitucional. No hay política si todas las opciones políticas, entre ellas el derecho de las comunidades a decidir como pueblos sus propios destinos, no se toman en consideración. No hacerlo implica presentar un resultado final prediseñado que, por muy deseable que parezca a algunos, ya cierra de antemano otras opciones políticas.

Lo que es ciertamente difícil es pretender que los colectivos se involucren a fondo con su sociedad política si saben que su opinión no tiene ninguna posibilidad de, al menos potencialmente, operar cambios en su entorno político. No basta con permitir al pueblo expresarse si su opinión no es vinculante en los asuntos de mayor calado. La sacralización del ordenamiento y la apelación al empleo de las fuerzas armadas (art. 8) no hace sino erosionar la legitimidad del ordenamiento.

Tomarse en serio la importancia de la adhesión ciudadana para la salud y estabilidad de un régimen democrático exige preguntarse cómo se fomenta este elemento

${ }^{25}$ Laclau, E. (1996). Emancipación y diferencia, Buenos Aires, Ariel. Mouffe, C. El retorno de lo político. Comunidad, ciudadanía, pluralismo, democracia radical. Trad. Marco Aurelio Galmarini. Barcelona, Paidós, 1999, p. 11. 
actitudinal, o al menos, cómo se impide que el descrédito y la indignación que recae sobre la impermeabilidad de las instituciones, unido a otros factores como el actual sistema electoral, el bipartidismo, las candidaturas de listas cerradas y bloqueadas, la corrupción, etc., acabe convirtiéndose en un cuestionamiento general a la propia democracia como sistema, pues esto sería de una gravedad mayor.

Desde la irrupción de los movimientos de indignados de 2011, el aparente contenido anti-institucional de muchas de las protestas ciudadanas no era sino la expresión de la decepción con las carencias del actual sistema democrático y la reivindicación de instituciones más representativas y permeables. No obstante, la reiterada falta de respuesta democrática a los deseos de mayor representatividad ciudadana puede acabar acentuando el riesgo de una indeseable deriva antidemocrática que ya comienza a atisbarse.

Sin embargo, como decía Hölderlin, donde anida el peligro crece también lo que salva. Un sistema jurídico ha de organizarse internamente con suficiente flexibilidad con el fin de mantener la existencia de la legalidad que instaura.

Puede que la mejor defensa de la democracia sea la profundización en la democracia: la radicalización democrática. No hay otra alternativa que no tenga ribetes totalitarios: ni la sustitución del sistema parlamentario por democracia asamblearia, ni la eliminación del concepto de representación por una democracia directa. El hecho de que la complejidad demográfica y política de los Estados modernos avale el protagonismo de mecanismos de representación no puede ser sinónimo de eliminación de la discusión pública de las cuestiones prácticas. En este sentido, no cabe hablar de oposición entre democracia directa y democracia representativa, sino, más correctamente, de democracia participativa, que puede ejercerse tanto de forma directa como por medio de representantes. ${ }^{26}$

La democracia representativa es un modelo de democracia que se basa en el concepto de representación, pero la democracia, sin adjetivos, no se agota en el voto que elige la representación, especialmente en sistemas de listas cerradas. Los ciudadanos eligen a quienes gobiernan en su nombre, pero esta cesión de soberanía en modo alguno puede entenderse como una donación/alienación (translatio), sino como un mandato o una delegación (concessio) a unos fideicomisarios que es susceptible de ser monitorizada por los titulares de la soberanía. ${ }^{27}$ Un régimen democrático representativo está instalado en una permanente tensión: la de establecer los mecanismos por medio de los cuales el pueblo gobernado sea al mismo tiempo el pueblo que gobierna. Por eso, la democracia no es un método dado de una vez

\footnotetext{
${ }_{26}$ Presno Linera, M. A., ¿Nos representan o no?, Anales de la Cátedra Francisco Suárez, 46, 2012, pp. 93-109.

${ }^{27}$ Locke, J., Dos Ensayos sobre el Gobierno Civil, edición de Joaquín Abellán, traducción de Francisco Giménez Gracia, Madrid, Espasa-Calpe, 1997, p. 149.
} 
por todas sino que es un modo imperfecto, revisable y abierto a las posibilidades de mejora.

Por tanto, la Constitución de un Estado democrático debería poder acoger estas posibilidades y ser parte de la solución y no del problema. Una Constitución para una democracia madura exige la apertura de mecanismos de control y cambio perfectamente reglados para que los ciudadanos puedan por voluntad propia proponer, modificar y reformar las reglas de actuación políticas, jugando un papel de vigilancia y control más activo. Ello no supone la eliminación de los mecanismos de representación parlamentaria, sino mas bien su complemento, haciendo posible la deseable vertiente conversacional que tiene la política en general y la democracia en particular. ${ }^{28}$

La relación entre gobernantes y gobernados no puede por tanto compartimentarse en emisores-tutores y receptores-tutelados, que es lo que sucede cuando la conversación democrática queda recluida en el marco de las Cámaras. Parece deseable abrir vías para que las propuestas de quienes van a ser los destinatarios de las normas, los ciudadanos, tengan la posibilidad real de que las decisiones que se tomen en las instituciones estén conectadas y abiertas a su escrutinio.

En la práctica esto supondría, al menos, la ampliación del artículo 87.3, abriendo el reconocimiento del derecho ciudadano a la iniciativa popular sin vetos y la ampliación del artículo 92, para reconocer, como hacía la Constitución de la Segunda República espańola, el derecho a solicitar la convocatoria de un referéndum con carácter vinculante para decidir sobre la propuesta, modificación o derogación de una Ley o para solicitar una reforma constitucional.

Esto no bastaría para romper el hiato que se abre entre gobernantes y gobernados, pero desde luego sería un paso crucial en esa dirección que haría más fácil la adopción de otro tipo de medidas convergentes hacia el mismo fin, como el aligeramiento del peso excesivo de las maquinarias de los grandes partidos, la apertura de mayor espacio a las iniciativas populares, la libre y abierta selección de los representantes políticos, el desbloqueo de listas electorales o la mejora de la proporcionalidad entre los votos obtenidos y los escańos. Todo ello aumentaría la percepción de que el pueblo gobernado es y actúa como su propio gobernante y de que las instituciones del Estado están a su servicio.

No creemos que estas puedan ser consideradas respuestas coyunturales ante un contexto de desapego o desgaste democrático como el actual, sino que dichas reformas podrían considerarse el derivado de una exigencia inherente al carácter

${ }^{28}$ Pettit, P., Republicanismo. Una teoría sobre la libertad y el gobierno, traducción de Antoni Domènech, Barcelona, Paidós, 1999, p. 21. 
fluido, permanentemente inacabado y en construcción del propio sistema democrático.

Resulta contradictorio que la voluntad de establecer una "sociedad democrática avanzada" que se proclama en el Preámbulo de la propia Constitución no solo no se materialice en la apertura de cauces de expresión jurídica ciudadana sino que dicho camino quede obturado desde el propio marco constitucional.

Una vez que han sido superados en buena medida los problemas de extensión, referidos al acceso universal a la titularidad de los derechos de ciudadanía, lo que resta es dar respuesta al problema de la intensión. Más de cuarenta años después de la aprobación de la actual Constitución, queda pendiente la tarea de profundizar en la democracia y eliminar las limitaciones no justificadas a la participación popular. El reto del caso espańol es el de alcanzar un punto de equilibrio estable entre la actual rigidez constitucional y una igualmente indeseable volatilidad normativa con el objetivo de armonizar la legalidad constitucional y el principio democrático. 


\section{Referencias Bibliográficas}

Aláez Corral, B., "Constitucionalizar la secesión para armonizar la legalidad constitucional y el principio democrático en Estados territorialmente descentralizados como España”, REAF núm. 22, octubre 2015, pp. 136-183.

Arendt, H., ¿Qué es política? traducción de Rosa Sala Carbó, Barcelona, Paidós, 1997.

Bobbio, N., "Per un lessico di teoria generale del diritto" (1975), en Bobbio, N., Contributi ad un dizionario giuridico, Torino, 1994, p. 233.

CIS, "Estudio no 3240", Barómetro de febrero, 2019.

Habermas, J., Facticidad y validez. Sobre el derecho y el Estado democrático de derecho en términos de teoría del discurso, introducción y traducción de M. Jiménez Redondo, Madrid, Trotta, 1998.

Hart, H. L. A., The Concept of Law, Oxford, Oxford University Press, 1961.

Holmes, S., "Precommitment and the Paradox of Democracy", en J. Elster y R. Slagstad (eds.), Constitutionalism and Democracy, Cambridge, Cambridge University Press, 1988. https://doi.org/10.1017/CBO9781139173629.008

Kelsen, H., Esencia y valor de la democracia, traducción de R. Luengo y L. Legaz, prólogo de I. de Otto, Barcelona, Labor, 1977.

Laclau, E. (1996). Emancipación y diferencia, Buenos Aires, Ariel.

Locke, J., Dos Ensayos sobre el Gobierno Civil, edición de Joaquín Abellán, traducción de Francisco Giménez Gracia, Madrid, Espasa-Calpe, 1997.

Mouffe, C. El retorno de lo político. Comunidad, ciudadanía, pluralismo, democracia radical, traducción de Marco Aurelio Galmarini. Barcelona, Paidós, 1999.

Pettit, P., Republicanismo. Una teoría sobre la libertad y el gobierno, traducción de Antoni Domènech, Barcelona, Paidós, 1999.

Presno Linera, M. A., ¿Nos representan o no?, Anales de la Cátedra Francisco Suárez, 46, 2012, pp. 93-109.

Rawls, J., El liberalismo político, traducción de Antoni Domènech, Barcelona, Crítica, 1996. 
Rawls, J., La justicia como equidad. Una reformulación, Edición a cargo de Erin Kelly, traducción de Andrés de Francisco, Barcelona, Paidós, 2002.

Spinoza, B., Tratado Político, traducción de Atilano Domínguez, Madrid, Alianza, 1986.

DOI: https://doi.org/10.15366/bp2019.22.015

Bajo Palabra. II Época. No 22. Pgs: 291-308 
